\title{
Regionalization of landscape pattern indices using multivariate cluster
}

\section{analysis}

Jed A. Long ${ }^{\mathrm{a} *}$, Trisalyn A. Nelson ${ }^{\mathrm{a}}$, Michael A. Wulder ${ }^{\mathrm{b}}$

${ }^{a}$ Spatial Pattern Analysis \& Research (SPAR) Laboratory, Dept of Geography, University of Victoria, PO Box 3060, Victoria, BC, V8W 3R4, Canada.

${ }^{\mathrm{b}}$ Canadian Forest Service (Pacific Forestry Centre), Natural Resources Canada, 506 West Burnside Road, Victoria, BC, V8Z 1M5, Canada.

*corresponding author:

Jed A. Long, email: jlong@uvic.ca, phone: (250) 853 - 3271

\section{Pre-print of published version.}

\section{Reference:}

Long, JA, TA Nelson, and MA Wulder. 2010. Regionalization of landscape pattern indices using multivariate cluster analysis.

Environmental Management. 46(1). 134-142.

\section{DOI:}

http://dx.doi.org/10.1007/s00267-010-9510-6

\section{Disclaimer:}

The PDF document is a copy of the final version of this manuscript that was subsequently accepted by the journal for publication. The paper has been through peer review, but it has not been subject to any additional copy-editing or journal specific formatting (so will look different from the final version of record, which may be accessed following the DOI above depending on your access situation).

Keywords: regionalization, landscape pattern indices, multivariate cluster analysis, spatial pattern regions (SPR), forest fragmentation 


\begin{abstract}
Regionalization, or the grouping of objects in space, provides a useful tool for organizing, visualizing, and synthesizing the information contained in multivariate spatial data. Landscape pattern indices can be used to quantify the spatial pattern (composition and configuration) of land cover features. Observable patterns can be linked to underlying processes affecting the generation of landscape patterns (e.g., forest harvesting). The objective of this research is to develop an approach for investigating the spatial distribution of forest pattern across a study area where forest harvesting, other anthropogenic activities, and topography, are all influencing forest pattern. We generate spatial pattern regions (SPR) that describe forest pattern with a regionalization approach. Analysis is performed using a 2006 land cover dataset covering the Prince George and Quesnel Forest Districts, 5.5 million ha of primarily forested land base situated within the interior plateau of British Columbia, Canada. Multivariate cluster analysis (with the CLARA algorithm) is used to group landscape objects containing forest pattern information into SPR. Of the six generated SPR, the second cluster (SPR2) is the most prevalent covering $22 \%$ of the study area. On average landscapes in SPR2 are comprised of $55.5 \%$ forest cover, and contain the highest number of patches, and forest/non-forest joins, indicating highly fragmented landscapes. Regionalization of landscape pattern metrics provides a useful approach for examining the spatial distribution of forest pattern. Where forest patterns are associated with positive or negative environmental conditions, SPR can be used to identify similar regions for conservation or management activities.
\end{abstract}

\title{
INTRODUCTION
}

Regionalization, or spatial classification, is the grouping of geographical entities based on properties or relationships (Chorley and Haggett 1967; Johnston 1968). Regionalization has long been a cornerstone of geographic data analysis (Haggett 1965), and has many purposes. For instance, regionalization is often applied to large, detailed geographical data sets to reduce data dimensionality and aid interpretation ( $\mathrm{Ng}$ and Han 2002). Examples of regionalization include ecozones (Schultz 2005), environmental domains (Leathwick and others 2003: Coops and others 2009), and spatially explicit regions relating to geology (Harff and Davis 1990), climate (Fovell and Fovell 1993) or agriculture (Lark 1998).

Interest in quantifying landscape patterns has been driven by the premise that some ecological processes can be linked to the spatial pattern of land cover elements (Gustafson 1998). Measurement of landscape pattern can be done using a subset of the numerous landscape pattern indices (landscape metrics) that currently exist (Cardille and others 2005). Given the advancement in methods for acquiring and storing spatial data, the spatial extent of landscape pattern studies has increased. Detailed land cover data is now available for the United States (Vogelmann and others 2001; Homer and others 2004) and Canada (Wulder and others 2008a), leading to large area landscape pattern studies (e.g., Riitters and others 2002; Wulder and others 2008b). Given the spatial extent available to landscape pattern studies, regionalization is a useful approach to aid in interpretation of large area landscape pattern information.

There are only a small number of examples in the peer-reviewed literature that explore how landscape pattern can be used in regionalization. MacPhail (1971) used aerial photography to map landscape patterns and related them to image fabric and 
textures to aid in the visual interpretation of different pattern regions. Similarly, Wickham and Norton (1994) created landscape pattern types, defined as a kilometre-wide geographical area, throughout which a limited number of land cover categories form a consistent pattern. Wickham and Norton (1994) employed visual interpretation of Landsat Thematic Mapper (TM) imagery in order to derive landscape pattern types. These studies took a qualitative approach using human interpretation and subjectivity for the regionalization process. A quantitative approach may be advantageous as it is more explicit, repeatable, transferable, and defensible (Hargrove and Hoffman 2004). Examples of quantitative approaches to mapping landscape spatial pattern also exist. Riitters and others (2000) developed a classification of forest fragmentation using two indices of spatial pattern. Forest fragmentation classes can then be mapped to examine the spatial distribution of forest fragmentation (globally, Riitters and others 2000; and in the United States, Riitters and others 2002). Morphological image processing (Soille 2003) has also been used for mapping forest components. Morphological image analysis algorithms classify forest patches as core, edge, or patch (Vogt and others 2007). The forest patch classes can then be mapped to provide information on the spatial arrangement of the landscape. In this work, we intend to expand on these previous examples using multivariate cluster analysis as the method for the regionalization process.

The goal of this study is to use regionalization for mapping forest pattern across a large area. To meet this goal, we implement multivariate cluster analysis as a quantitative approach to regionalizing forest pattern. Multivariate cluster analysis provides a new approach to the regionalization of landscape patterns. Landscape pattern indices are calculated and cluster analysis is performed on these metrics to generate Spatial Pattern Regions (SPR). SPR represent landscape units that exhibit similar forest pattern characteristics. By mapping SPR we can explore the spatial distribution of forest pattern across our study area. In a region of British Columbia, Canada, where increased forest harvesting is occurring due to insect salvage and mitigation activities, SPR are used to identify the spatial distribution of forest pattern.

\section{METHODS \\ Study Area}

Two adjacent forest districts within British Columbia, Canada were chosen as the study area (Fig. 1). The Prince George and Quesnel Forest Districts cover 5.5 million hectares of primarily forested land base. The climate in the Prince George and Quesnel Forest Districts is characterized by long, cold winters interspersed with hot, humid summers (Meidinger and Pojar 1991). Forests here are comprised primarily of lodgepole pine (Pinus contorta), white spruce (Picea glauca), and sub-alpine fir (Abies lasiocarpa).

$$
<\text { Approximate location for Figure } 1>
$$

Currently, the largest recorded mountain pine beetle (Dendroctonus ponderosae) infestation is occurring in British Columbia, causing extensive mortality in lodgepole pine stands. The range of infestation is estimated to have increased from 166,000 ha in 1999 to 10.1 million ha in 2007 (Westfall and Ebata 2008). Short-term increases to the provincial allowable annual cut have been prescribed in the Prince George and Quesnel Forest Districts as a means to recover economic value from infested timber (British Columbia Ministry of Forests and Range 2007). The increased allowable annual cut will 
facilitate salvage harvest opportunities, which are expected to impact resulting forest patterns.

\section{Data}

A 2006 land cover dataset was generated for the calculation of landscape pattern metrics. Using a change detection method based on Landsat Thematic Mapper (TM) and Enhanced Thematic Mapper (ETM+) data (Han and others 2007), we updated forest conditions of an existing land cover dataset produced by the Earth Observation for Sustainable Development of Forests (EOSD) program (Wulder and others 2003; 2008a). Land cover is represented at a spatial resolution of $25 \mathrm{~m}$, with up to 23 classes of categorical detail, which can be aggregated to forest, non-forest, and other classes (Wulder and Nelson 2003). The forest, non-forest, and other categories are useful for examining the spatial pattern of forests, and are comparable to land cover categories used for forest fragmentation studies in Canada (Wulder and others 2008b) and the United States (Riitters and others 2002).

A regular squared partition (fishnet) was used to generate an encompassing set of smaller analysis units (landscapes) within the study region. A $1 \mathrm{~km}$ landscape was chosen to capture the impacts of forest harvesting and insect salvage and mitigation activities. Larger landscape sizes exhibit varying levels of spatial pattern, while smaller landscape sizes tend towards a bifurcation of forest patch or no patch. In Canada, a $1 \mathrm{~km}$ landscape has been used for forest fragmentation reporting and identified as an appropriate scale for provincial and regional studies (Wulder and others 2008b).

\section{Analysis}

\section{Landscape Pattern Variables}

Many metrics exist for quantifying the spatial pattern of land cover. It is typically appropriate to choose a subset of metrics relevant to a specific application (Gergel 2007). Previous work has used correlation analysis to identify key components of landscape spatial pattern (e.g., Riitters and others 1995). Others have based selection of metrics on background literature identifying the key components of spatial pattern (e.g., Hargis and others 1997; Boots 2006). Regardless, it is imperative to select applicable indices for any given study, and a small number of uncorrelated metrics are often sufficient to quantify the relevant aspects of pattern for any specific application (Gergel 2007).

We select five indices of landscape pattern (Table 1) to quantify forest pattern for regionalization. Class proportion effectively defines the composition of the landscape in two class landscapes (Boots 2006) and researchers have demonstrated that class proportion is the driving factor of landscape spatial pattern (Boots 2006; Remmel and others 2002). Join counts are useful in quantifying the level of spatial clustering (sometimes calculated as contagion, see Li and Reynolds 1993) in landscape components and can be related to edge, an important aspect of habitat (Ranney and others 1981). Landscape fragmentation can be monitored using number of patches (Haines-Young and Chopping 1996). When quantifying patch area, Boots (2006) suggests that the sum of squared area of patches provides more information than average patch area, as it is sensitive to patch size distribution (e.g., the difference between one large and one small patch, and two medium patches). Thus, we have chosen to use an area squared measure to quantify the areal properties of patches. Patch perimeter-area ratio is useful in monitoring the regularity/complexity of patch shapes. Generally, natural landscapes exhibit complex, irregular shapes (Forman 1995), while anthropogenic landscapes contain regular shapes 
and straight edges (Hammett 1992; Forman 1995), and we employ the mean patch perimeter-area ratio to quantify these differences.

\section{Multivariate Cluster Analysis}

\section{$<$ Approximate location for Table $1>$}

Cluster analysis has been referred to as the art of finding groups in data (Kaufman and Rousseeuw 1990). More specifically, cluster analysis is a quantitative statistical method that uses unsupervised learning to explore, find, and categorize features, and to gain insight on the nature or structure of data (Duda and others 2001).

The CLARA (Clustering for LARge Applications) algorithm (Kaufman and Rousseeuw 1990) was used to perform cluster analysis. CLARA is a flat-partition method that has been specifically designed for use with large datasets. User definition of the $k$ parameter (the output number of clusters) is required, and since $k$ is unknown we implement the algorithm for a range of $k$ values (2-10). An optimal clustering level $(k)$ can be chosen iteratively using evaluative criteria that identify a $k$ value for which the clustering is strongest (Milligan and Cooper 1985; Halkidi and others 2002).

\section{Normalization and Weighting}

Normalized (standardized) data are necessary for cluster analysis. We normalize our data following Kaufman and Rousseeuw (1990):

$$
z_{i f}=\frac{x_{i f}-m_{f}}{s_{f}}
$$

where $z_{i f}$ is the normalized value for observation $i$ of variable $f, x_{i f}$ is the original value for observation $i$ of variable $f, m_{f}$ is the mean of variable $f$, and $s_{f}$ is a measure of dispersion for variable $f$. We use the mean absolute deviation as the measure of dispersion which is defined as:

$$
s_{f}=\frac{1}{n}\left\{\left|x_{1 f}-m_{f}\right|+\left|x_{2 f}-m_{f}\right|+\cdots+\left|x_{n f}-m_{f}\right|\right\}
$$

where $n$ is the number of observations. This dispersion measure is more robust than the typically used standard deviation and is therefore recommended (Kaufman and Rousseeuw 1990).

A priori knowledge can be a useful tool to improve a clustering by adding weight to given attributes (e.g., Abrahamowicz 1985). In the absence of quantitative information, expert opinion is used to assign weights to input variables on a case specific basis. In consideration of the relative importance of land cover composition over configuration metrics (Gustafson and Parker 1992; Fahrig 1997; Remmel and others 2002; Boots 2006), we increase the weighting of the class proportion metric by a factor of two over the other metrics in our study.

Early in our analysis, we identified two landscape groups that were impacting results: regions containing either $0 \%$ or $100 \%$ forest. Prior to analysis, we grouped these two groups into two intuitive clusters, SPR0 and SPR100, representing the proportion of forest in each.

Spatial weighting can be a useful tool in regionalization when the end goal is to define spatially contiguous regions (see Oliver and Webster 1989 for a discussion on spatial weights). However, with forest pattern we expect spatially disjointed or distanced regions to exhibit similar forest patterns (e.g., separated by natural or anthropogenic features). As such, when identifying new/different locations with similar characteristics, methods not including spatial weighting are preferred (Coops and others 2009). We 
exclude spatial weighting for the generation of SPR because of the expectation of spatially distanced landscapes with similar forest patterns.

\section{Measure of Separation}

With cluster analysis it is necessary to calculate a measure of separation between objects. The use of the Euclidean distance measure is common in regionalization (e.g., Fovell and Fovell 1993; Gong and Richman 1995), and is easily computed on standardized variables in attribute space. Euclidean distance was implemented as the measure of separation between objects. In this example, we employed only intervalscaled variables, however, when using binary, ordinal, nominal, or some mixture of variable types, other separation measures become more appropriate (Kaufman and Rousseeuw 1990).

\section{Cluster Evaluative Criteria}

The Davies-Bouldin index (DB) (Davies and Bouldin 1979) and average silhouette width (ASW) (Kaufman and Rousseeuw 1990) were chosen as evaluative criteria for selecting the optimal $k$. Measures of cluster strength frequently suggested are often tested on datasets with clearly defined clusters (e.g., Milligan and Cooper 1985). While these measures are known to work well with clusters that are compact, novel approaches are needed to test cluster validity when the data does not exude compact clusters, as with spatial data (Halkidi and others 2002). Strongly defined clusters are not expected here, as landscapes vary continuously over the range of metrics tested.

ASW is calculated using [3], which is a measure of how well clusters are separated from their closest neighbour (Kaufman and Rousseeuw 1990).

$$
A S W=\frac{1}{k} \sum_{i=1}^{k} \frac{b_{i}-a_{i}}{\max \left\{b_{i}, a_{i}\right\}}
$$

Where $a$ is the average dissimilarity between objects in a cluster $i, b$ is the average dissimilarity of the objects in $i$ to those in its closest neighbour, and $k$ is the number of clusters. The maximal ASW for all $k$ is interpreted as the optimal or strongest cluster level (Kaufman and Rousseeuw 1990). ASW values of 0.71-1.00 indicate a $k$ with well defined clusters, while ASW values of $0.26-0.50$ indicate a $k$ with weakly defined or artificial clusters, (Kaufman and Rousseeuw 1990).

DB uses a ratio of intra-cluster dispersion to inter-cluster separation divided by $k$ to determine clustering strength for a given $k$ [4] (Davies and Bouldin 1979).

$$
D B=\frac{1}{k} \sum_{i=1}^{k} \frac{S_{i}+S_{j}}{m_{i j}}
$$

Where $S_{i}$ is the dispersion of cluster $i, S_{j}$ is the dispersion of the next closest cluster $j, m_{i j}$ is the distance between the cluster centers of $i$ and $j$, and $k$ is the number of clusters. DB is advantageous in that it does not require user definition of parameters, such as minimum acceptable cluster distance or minimum acceptable standard deviation, which are often unknown (Davies and Bouldin 1979). Optimal $k$ is found at the minimum DB value; when intra-cluster dispersion is low and inter-cluster separation is high.

In this study, the output clusters of multivariate cluster analysis are termed spatial pattern regions (SPR): regions that exhibit similar forest patterns. Multivariate cluster analysis allows users to examine many statistical and qualitative properties of each cluster. Descriptive statistics, such as mean, median, and coefficient of variation, were computed for each SPR and landscape metric combination. We generate the relative 
frequency histogram for each SPR and landscape pattern metric combination to assess the distributional properties of each SPR. Also, each cluster that is created by the CLARA algorithm has a medoid, which is a representative object for each cluster and is used as a surrogate center for each cluster (Kaufman and Rousseeuw 1987). Medoids are less sensitive to outliers than other cluster profiles (Van Der Laan and others 2003). With the CLARA algorithm, we extract each medoid and use it as a visual representation for each generated SPR.

\section{RESULTS}

Using cluster evaluative criteria (DB and ASW), an optimal cluster level was identified at $k=6$ (Figure 2). In Fig. 2, we see that DB is minimal at $k=6$, and ASW is maximum at $k=2$, but has a second peak when $k=6$. We chose $k=6$ as the optimal clustering over the case when $k=2$ based on the evaluative criteria, and also because the case where $k=2$ provides few unique insights on landscape processes (largely representing a bifurcation of landscapes with high and low forest composition).

$$
<\text { Approximate location for Figure } 2>
$$

Mean, median, and coefficient of variation for each of the 6 generated SPR were calculated (Table 2). Mean forest proportion increases from SPR1 (18.9\%) to SPR5 $(93.5 \%)$, and then decreases to SPR6 $(88.3 \%)$. The variation in forest proportion is highest when forest proportion is low (i.e., in SPR1, c.v. =0.60). Number of patches is highest in SPR2 (mean $=24.0)$ and lowest in SPR6 (mean = 5.2). Forest/non-forest joins are highest in SPR2 (mean $=629.5$ joins). Patch areas based on the area-squared measure are largest in SPR5 $\left(\right.$ mean $\left.=7172 \mathrm{ha}^{2}\right)$ and smallest in SPR2 (mean $\left.=3481 \mathrm{ha}^{2}\right)$. Average perimeter-area ratio is highest in SPR4 (mean $=955.0 \mathrm{~m} / \mathrm{ha}$ ), and there is a marked difference between the lowest SPR6 (mean $=527.6 \mathrm{~m} / \mathrm{ha}$ ) and the next lowest SPR3 (mean $=752.3 \mathrm{~m} / \mathrm{ha})$. SPR4, SPR5, and SPR6 all have high forest composition (mean $>$ $80 \%$ ), however, SPR4 and SPR5 have high perimeter area ratios (mean $=955.0 \mathrm{~m} / \mathrm{ha}$, $879.6 \mathrm{~m} / \mathrm{ha}$, respectively) relative to SPR6 (mean $=527.6 \mathrm{~m} / \mathrm{ha})$.

\section{$<$ Approximate location for Table $2>$}

We computed the relative frequency histogram of landscape metrics for each SPR (Fig. 3). SPR2 and SPR3 have similar distributions for forest proportion. Configurational attributes for SPR2 and SPR3 differ considerably in number of patches and forest/nonforest joins. Based on Table 2, we would expect SPR4, SPR5 and SPR6 to have similar forest proportions, but there is a noticeable difference in the distribution of SPR4 from SPR5 and SPR6. The relative frequency distribution for SPR4's number of patches and forest/non-forest joins differ when compared to SPR5 and SPR6. SPR5 and SPR6 have similar distributions for most of the spatial pattern metrics, but differ in number of patches and average perimeter area ratio. The relative frequency distribution of perimeter-area ratio for SPR6 is unique in comparison with other SPR.

$$
<\text { Approximate location for Figure } 3>
$$

We extracted the medoid landscape for each SPR (Fig. 4). The medoid provides a visual representation of the type of landscape found in each SPR. This information is useful in interpreting results, as it is a visual reference of observed forest pattern. Multivariate cluster analysis is a quantitative approach to regionalization, however, the medoid landscape represents a qualitative descriptor for each SPR.

$$
<\text { Approximate location for Figure } 4>
$$


A map of the distribution of SPR can be viewed in Fig. 5. We included a digital elevation model (DEM) to aid in interpretation. SPR0 and SPR100 represent the least frequent SPR in the study area, constituting $2 \%$ and $4 \%$ of the total area (Table 3). SPR2 $(22 \%)$ has the largest area, while SPR1 (9\%) has the smallest area. Topography, especially along the eastern edge of our study area, plays an important role in landscape spatial pattern. Valleys contain SPR5 and SPR6, regions with high levels of forest composition and low number of forest patches. Alpine areas are associated with SPR0, SPR1, SPR2, and SPR3, regions with low forest composition, high numbers of patches, and high forest/non-forest joins. The topographic influence on land cover in alpine area results in these regions being labelled the same as disturbed forest landscapes (e.g., from harvesting, natural disturbance). In reality, the patterns observed in alpine areas are natural, and should be distinguished from low lying areas where landscape pattern originates from some other process using ancillary information such as a digital elevation model (DEM) or land cover information. Anthropogenic activities are expected to be highest near the cities of Prince George and Quesnel (see study area, Fig. 1). These areas show up as predominantly SPR1, SPR2, and SPR3, the SPR with the lowest forest proportion and highest number of patches. In the western portion of the Quesnel Forest District (the lower left portion of Fig. 5), noticeable pockets of SPR100 (continuous forest) and SPR5 and SPR6 (high forest proportion, low number of patches), are interspersed with pockets of SPR1, SPR2, and SPR3 (low forest proportion, high number of patches). The mixture of fragmented and intact forest here may be an indication of the types of forest harvesting occurring in this area. Where topography is less extreme and has less of an influence on the spatial pattern of the landscape, forest harvesting activities are expected to be the driving factor in shaping observed forest patterns.

$$
\begin{aligned}
& <\text { Approximate location for Figure } 5> \\
& <\text { Approximate location for Table } 3>
\end{aligned}
$$

\section{DISCUSSION}

Using landscape pattern indices and a $1 \mathrm{~km}$ analysis unit, we generated SPR, landscape units exhibiting similar forest pattern characteristics. The landscape pattern indices employed in this study are only a small subset of the suite of metrics available to researchers, and the choice of metrics should be related to the research purpose (Gergel 2007). In this study, we are interested in monitoring forest fragmentation in a study area where post insect infestation salvage and mitigation related forest harvesting has occurred. We employ metrics useful for quantifying the key components of landscape pattern related to forest fragmentation (Haines-Young and Chopping 1996, Wulder and others 2008b).

Forest fragmentation can be defined as the breaking up of forest into smaller and more numerous parcels (Forman 1995). We use this definition for labelling SPR as a forest fragmentation gradient going from SPR1 (highly fragmented) to SPR6 (low fragmentation, with SPR0 and SPR100 providing external bounds of no and all forest, respectively. Alternatively, researchers have used forest composition as a proxy for quantifying forest fragmentation due to the difficulty associated with interpreting composition and configuration metrics simultaneously (e.g., Wickham and others 2008). SPR provide a useful method for incorporating both composition and configuration measurements in forest fragmentation analysis across large areas. 
Generation of relative frequency histograms for each SPR-metric combination proved to be useful for interpretation of SPR properties. For example, based solely on tabulated results, SPR4, SPR5, and SPR6 exhibit similar forest composition levels. The use of relative frequency histograms provides added information on SPR4 as it exudes a noticeably different distribution from SPR5 and SPR6. Similarly, extracting each medoid landscape provides a useful visual representation for each SPR.

Any multivariate cluster analysis is dependant on the data, input parameters, and methods applied. We provide an example of multivariate cluster analysis using the CLARA algorithm and two tests for determining the optimal clustering (DB and ASW). Changing the clustering algorithm or the evaluative criteria will impact results. As it was specifically designed for large datasets, the CLARA algorithm is suited for large spatial datasets, where other methods (e.g., hierarchical) are computationally constrained. It is up to the user to explore combinations of algorithms and criteria that are useful and relevant for their research.

This study was conducted in a region where increased forest harvesting has been prescribed in response to insect infestation (British Columbia Ministry of Forests and Range 2007). In the eastern part of the study area, an examination of the spatial distribution of SPR suggests that topographical influence on land cover is a key factor affecting forest pattern. Not surprisingly, the highest levels of forest fragmentation occur in areas with the most anthropogenic activity, located centrally in the study area. In the western portion, especially in the Quesnel Forest District, parcels of fragmented landscapes (SPR1, SPR2, and SPR3) are interspersed with non-fragmented landscapes (SPR5, SPR6, and SPR100). In the Quesnel Forest District, mountain pine beetle infestation is widespread, with salvage and mitigation harvesting activities likely driving the forest pattern. In the western region where anthropogenic impacts are shaping forest pattern, further investigation of natural processes, such as wildlife habitat loss (Bunnell and others 2004) and hydrologic regimes (Helie and others 2005) may be required.

\section{CONCLUSION}

Current international forest monitoring initiatives cite forest fragmentation as a new indicator for reporting (e.g., Montreal Process Liaison Office 2000). Thus effective methods quantifying forest pattern across large areas are required to meet these goals. In Canada, the spatial extent of forest monitoring limits our ability to visualize and interpret forest pattern information. Similarly, the number of attributes required to effectively monitor forest pattern is not easily visualized with maps. Regionalization may provide an effective approach for meeting these monitoring directives.

In this research we demonstrate regionalization as an effective approach for mapping similarities and differences in landscape forest pattern. Regionalization provides a quantitative approach for grouping spatial units into categories based on a given set of attributes. Mapping SPR can benefit a variety management and conservation activities. If the forest pattern in a region has been identified as favourable or problematic, for a specific management goal, other areas with similar conditions can be identified. For instance, wildlife often prefer habitat with particular forest patterns; for example, American Martens in the Uinta Mountains of northern Utah are rarely detected in forest landscapes with $>25 \%$ area open, but may prefer landscapes with low levels of fragmentation with contiguous forest openings (Hargis and others 1999). Using a 
regionalization approach, such as SPR, locations that exhibit landscape pattern attributes preferred by American Martens, can be identified as potential habitat. Given the importance of landscape pattern for many ecological processes, regionalization of landscape pattern indices is a useful approach for examining the spatial distribution of landscape pattern.

\section{Acknowledgements}

This project was funded by the Government of Canada through the Mountain Pine Beetle Program, a six-year, $\$ 40$ million program administered by Natural Resources Canada, Canadian Forest Service. Additional information on the Mountain Pine Beetle Program may be found at: http://mpb.cfs.nrcan.gc.ca. Chris Butson and Xiaoping Yuan of the British Columbia Ministry of Forests and Range and Joanne White of the Canadian Forest Service are thanked for insight and access to data critical to the success of this research. Thanks to Dennis Jelinski for helpful comments on earlier versions of this manuscript. 


\section{REFERENCES}

Abrahamowicz M (1985) The use of non-numerical a priori information for measuring dissimilarities. Paper presented at the Fourth European Meeting of the Psychometric Society and the Classification Societies, July 2-5, Cambridge, UK

British Columbia Ministry of Forests and Range (2007) Timber supply and the mountain pine beetle infestation in British Columbia: 2007 update. British Columbia Ministry of Forests and Range, Forest Analysis and Inventory Branch, Victoria, BC. $38 \mathrm{pp}$

Boots B (2006) Local configuration measures for categorical spatial data: binary regular lattices. Journal of Geographical Systems 8:1-24

Bunnell FL, Squires KA, Houde I (2004) Evaluating effects of large-scale salvage logging for mountain pine beetle on terrestrial and aquatic vertebrates. Pacific Forestry Centre, Canadian Forest Service, Natural Resources Canada, Victoria, BC. $57 \mathrm{pp}$

Cardille J, Turner MG, Clayton M, Gergel SE, Price S (2005) METALAND: characterizing spatial patterns and statistical context of landscape metrics. BioScience. 55: 983-988

Chorley RJ, Haggett P (1967) Models in Geography. Methuen, London. 816pp

Coops, NC, Wulder, MA, Iwanicka D (2009) An environmental domain classification of Canada using earth observation data for biodiversity assessment. Ecological Informatics 4:8-22.

Davies DL, Bouldin DW (1979) A cluster separation measure. IEEE Transactions on Pattern Analysis and Machine Intelligence 1:224-227

Duda RO, Hart PE, Stork DG (2001) Pattern Classification. John Wiley and Sons, New York. 654 pp

Fahrig L (1997) Relative effects of habitat loss and fragmentation on population extinction. The Journal of Wildlife Management 61:603-610

Forman RTT (1995) Land mosaics: the ecology of landscapes and regions. Cambridge University Press, Cambridge, UK. 632 pp

Fovell RG, Fovell MYC (1993) Climate zones of the conterminous United States defined using cluster analysis. Journal of Climate 6:2103-2135

Gergel SE (2007) New directions in landscape pattern analysis and linkages with remote sensing. In: Wulder MA, Franklin SE (eds) Understanding forest disturbance and spatial pattern: remote sensing and GIS approaches. Taylor and Francis Group, Boca Raton, FL, pp 173-208

Gong X, Richman MB (1995) On the application of cluster analysis to growing season and precipitation data in North America East of the Rockies. Journal of Climate 8:897-931

Gustafson EJ (1998) Quantifying landscape spatial pattern: what is the state of the art? Ecosystems 1:143-156

Gustafson EJ, Parker GR (1992) Relationships between land cover proportion and indices of landscape spatial pattern. Landscape Ecology 7:101-110

Haggett P (1965) Locational analysis in Human Geography. Edward Arnold Ltd, London, $339 \mathrm{pp}$ 
Haines-Young R, Chopping M (1996) Quantifying landscape structure: a review of landscape indices and their application to forested landscapes. Progress in Physical Geography 20:418-445

Halkidi M, Batistakis Y, Vazirgiannis M (2002) Clustering validity checking methods: part II. SIGMOD Record 31:19-27

Hammett, JE (1992) The shapes of adaptation: historical ecology of anthropogenic landscapes in the Southeastern United States. Landscape Ecology 7:121-135

Han T, Wulder MA, White JC, Coops NC, Alvarez MF, Butson C (2007) An efficient protocol to process Landsat images for change detection with tasselled cap transformation. IEEE Geoscience and Remote Sensing Letters 4:147-151

Harff J, Davis JC (1990) Regionalization in geology by multivariate classification. Mathematical Geology 22:573-588

Hargis CD, Bissonette JA, David JL (1997) Understanding measures of landscape pattern. In Bissonette JA (ed) Wildlife and landscape ecology: effects of pattern and scale. Springer-Verlag, New York, NY, pp 231-261

Hargis CD, Bissonette JA, Turner DL (1999) The influence of forest fragmentation and landscape pattern on American martens. Journal of Applied Ecology 36:157-172

Hargrove WW, Hoffman FM (2004) Potential of multivariate quantitative methods for delineation and visualization of ecoregions. Environmental Management 34:S39S60

Helie JF, Peters DL, Tattrie KR, Gibson JJ (2005) Review and synthesis of potential hydrologic impacts of mountain pine beetle and related harvesting activities in British Columbia. Natural Resources Canada, Canadian Forest Service, Pacific Forestry Centre, Mountain Pine Beetle Initiative Working Paper 2005-23, Victoria, BC, $26 \mathrm{pp}$

Homer C, Huang C, Yang L, Wylie B, Coan M (2004) Development of a 2001 national land-cover database for the United States. Photogrammetric Engineering and Remote Sensing. 70:829-840.

Johnston R.J (1968) Choice in classification: the subjectivity of objective methods. Annals of the Association of American Geographers 58:575-589

Kaufman L, Rousseeuw PJ (1987) Clustering by means of medoids. In: Dodge Y (ed) Statistical data analysis based on the $\mathrm{L}_{1}$ norm and related methods. Elsevier, North Holland, pp 405-416

Kaufman L, Rousseeuw PJ (1990) Finding groups in data. John Wiley and Sons, New York, $342 \mathrm{pp}$

Lark RM (1998) Forming spatially coherent regions by classification of multi-variate data: an example from the analysis of maps of crop yield. International Journal of Geographical Information Science 12:83-98

Leathwick JR, Overton JM, McLeod M (2003) An environmental domain classification of New Zealand and its use as a tool for biodiversity management. Conservation Biology 17:1612-1623

Li H, Reynolds JF (1993) A new contagion index to quantify spatial patterns of landscapes. Landscape Ecology 8:155-162

MacPhail DD (1971) Photomorphic mapping in Chile. Photogrammetric Engineering 37:1139-1148 
Meidinger D, Pojar J (1991) Ecosystems of British Columbia. Research Branch British Columbia Ministry of Forests. Special Report Series Vol. 06, Victoria, BC, 330 $\mathrm{pp}$

Montreal Process Liaison Office (2000) Montreal process year 2000 progress report: progress and innovation in implementing criteria and indicators for the conservation and sustainable management of temperate and boreal forests. The Montreal Process Liaison Office, Canadian Forest Service, Ottawa, Canada Milligan GW, Cooper MC (1985) An examination of procedures for determining the number of clusters in a data set. Psychometrika 50:159-179

$\mathrm{Ng}$, RT, Han, J (2002) CLARANS: a method for clustering objects for spatial data mining. IEEE Transactions on Knowledge and Data Engineering 14:1003-1016

Oliver MA, Webster, R (1989) A geostatistical basis for spatial weighting in multivariate classification. Mathematical Geology 21:15-35

Ranney JW, Bruner MC, Levenson, JB (1981) The importance of edge in the structure and dynamics of forest islands. In: Burgess RL, Sharpe DM (eds) Forest island dynamics in man-dominated landscapes. Springer-Verlag, New York, NY, pp 6796

Remmel TK, Csillag F, Mitchell SW, Boots B (2002) Empirical distributions of landscape pattern indices as functions of classified image composition and spatial structure. Joint Symposium on Geospatial Theory, Processing and Applications, Ottawa, ON, $10 \mathrm{pp}$

Riitters KH, O'Neill, RV, Hunsaker CT, Wickham JD, Yankee DH, Timmins SP, Jones KB, Jackson BL (1995) A factor analysis of landscape pattern and structure metrics. Landscape Ecology 10:23-29

Riitters KH, Wickham JD, O'Neill RV, Jones KB, Smith ER (2000) Global-scale patterns of forest fragmentation. Ecology and Society (formerly Conservation Ecology) 4:article 3

Riitters KH, Wickham JD, O'Neill RV, Jones KB, Smith ER, Coulston JW, Wade TG, Smith, JH (2002) Fragmentation of continental United States forests. Ecosystems $5: 815-822$

Schultz J (2005) The ecozones of the world. Springer-Verlag, Berlin, 252 pp

Soille P (2003) Morphological image analysis: principles and applications, 2nd ed. Springer-Verlag, Berlin. 252 pp

Van Der Laan MJ, Pollard KS, Bryan J (2003) A new partitioning around medoids algorithm. Journal of Statistical Computation and Simulation 73:575-584

Vogelmann JE, Howard SM, Yang L, Larson CR, Wylie B, Van Driel JN (2001) Completion of the 1990s national land cover data set for the conterminous United States from Landsat Thematic Mapper data and ancillary data sources. Photogrammetric Engineering and Remote Sensing. 67:650-662

Vogt P, Riitters KH, Estreguil C, Kozak J, Wade TG, Wickham JD (2007) Mapping spatial patterns with morphological image processing. Landscape Ecology 22:171-177

Westfall J, Ebata T (2008) 2007 Summary of forest health conditions in British Columbia. Ministry of Forests and Range, Forest Practices Branch, Victoria, BC, $81 \mathrm{pp}$ 
Wickham JD, Norton DJ (1994) Mapping and analyzing landscape patterns. Landscape Ecology 9:7-23

Wickham JD, Riitters KH, Wade TG, Homer C (2008). Temporal change in fragmentation of continental US forests. Landscape Ecology 23:891-898

Wulder MA, Dechka JA, Gillis MD, Luther JE, Hall RJ, Beaudoin A, Franklin SE (2003) Operational mapping of the land cover of the forested area of Canada with Landsat data: EOSD land cover program. The Forestry Chronicle 79:1075-1083

Wulder, MA, Nelson T (2003) EOSD land cover classification legend report: version 2. Natural Resources Canada, Canadian Forest Service, Pacific Forestry Centre, Victoria, BC. $81 \mathrm{pp}$

Wulder MA, White JC, Cranny M, Hall RJ, Luther JE, Beaudoin A, Goodenough DG, Dechka JA (2008a) Monitoring Canada's forests - Part 1: completion of the EOSD land cover project. Canadian Journal of Remote Sensing 34:549-562

Wulder MA, White JC, Han T, Coops NC, Cardille J, Holland T, Grills D (2008b) Monitoring Canada's forests - Part 2: national forest fragmentation and pattern. Canadian Journal of Remote Sensing 34:563-584 
Table 1: Metrics chosen for multivariate cluster analysis and their formulation.

\begin{tabular}{ccc}
\hline Metric & Units & Formulation \\
\hline Class Proportion & $\%$ & $\frac{\sum a_{i}}{A} \rightarrow\{i=F\}$ \\
Join Counts & $\#$ & $\sum g_{j k} \rightarrow\{j=F, k=N\}$ \\
Number of Patches & $\#$ & $\sum n_{i} \rightarrow\{i=F, N, O\}$ \\
$\begin{array}{c}\text { Patch Area } \\
\text { Squared } \\
\text { Mean Patch } \\
\text { Perimeter-Area } \\
\text { Ratio }\end{array}$ & ha $^{2}$ & $\sum a_{i}^{2} \rightarrow\{i=F, N, O\}$ \\
\hline m/ha & $\frac{1}{n} \sum \frac{p_{i}}{a_{i}} \rightarrow\{i=F, N, O\}$
\end{tabular}

$A$ - total area of landscape, $a$ - area of patch, $g$ - join between two neighbouring cells, $n$ number of patches, $p$ - perimeter of patch, $F$ - forest, $N$ - non-forest, $O$ other. 
Table 2: Mean, median, and coefficient of variation for each metric-SPR combination.

\begin{tabular}{|c|c|c|c|c|c|c|}
\hline & (units) & $\begin{array}{c}\text { Forest } \\
\text { Proportion } \\
(\%)\end{array}$ & $\begin{array}{c}\text { Number of } \\
\text { Patches } \\
\text { (\#) }\end{array}$ & $\begin{array}{l}\text { Forest/Non- } \\
\text { Forest Joins } \\
\text { (\#) }\end{array}$ & $\begin{array}{c}\text { Squared } \\
\text { Area of } \\
\text { Patches } \\
\left(\mathrm{ha}^{2}\right)\end{array}$ & $\begin{array}{c}\text { Average } \\
\text { Patch } \\
\text { Perimeter } \\
\text { Area Ratio } \\
\text { (m/ha) }\end{array}$ \\
\hline \multirow{2}{*}{ SPR1 } & mean & 18.9 & 14.9 & 277.3 & 5647 & 831.1 \\
\hline & median & 19 & 15 & 284 & 5484 & 838.9 \\
\hline$n=5271$ & c.v. & 0.60 & 0.40 & 0.49 & 0.24 & 0.14 \\
\hline \multirow{2}{*}{ SPR2 } & mean & 55.5 & 24.0 & 629.5 & 3481 & 889.2 \\
\hline & median & 57 & 23 & 616 & 3442 & 888.7 \\
\hline$n=12150$ & c.v. & 0.25 & 0.26 & 0.21 & 0.21 & 0.08 \\
\hline \multirow{2}{*}{ SPR3 } & mean & 65.7 & 12.7 & 367.6 & 4021 & 752.3 \\
\hline & median & 68 & 13 & 362 & 3964 & 762.6 \\
\hline$n=11548$ & c.v. & 0.19 & 0.29 & 0.28 & 0.22 & 0.14 \\
\hline \multirow{2}{*}{ SPR4 } & mean & 84.7 & 21.4 & 371.1 & 5907 & 955.0 \\
\hline & median & 85 & 20 & 365 & 5917 & 952.0 \\
\hline$n=8027$ & c.v. & 0.07 & 0.28 & 0.27 & 0.13 & 0.08 \\
\hline \multirow{2}{*}{ SPR5 } & mean & 93.5 & 9.7 & 153.4 & 7172 & 879.6 \\
\hline & median & 95 & 10 & 148 & 7315 & 871.6 \\
\hline$n=10034$ & c.v. & 0.05 & 0.35 & 0.50 & 0.09 & 0.11 \\
\hline \multirow{2}{*}{ SPR6 } & mean & 88.3 & 5.2 & 137.6 & 6675 & 527.6 \\
\hline & median & 92 & 5 & 128 & 6959 & 585.9 \\
\hline$n=5775$ & c.v. & 0.15 & 0.49 & 0.62 & 0.18 & 0.34 \\
\hline
\end{tabular}


Table 3: Area percentages of each SPR.

\begin{tabular}{cc}
\hline SPR & Area $(\boldsymbol{\%})$ \\
\hline SPR0 & 2 \\
SPR1 & 9 \\
SPR2 & 22 \\
SPR3 & 21 \\
SPR4 & 14 \\
SPR5 & 18 \\
SPR6 & 10 \\
SPR100 & 4 \\
\hline
\end{tabular}




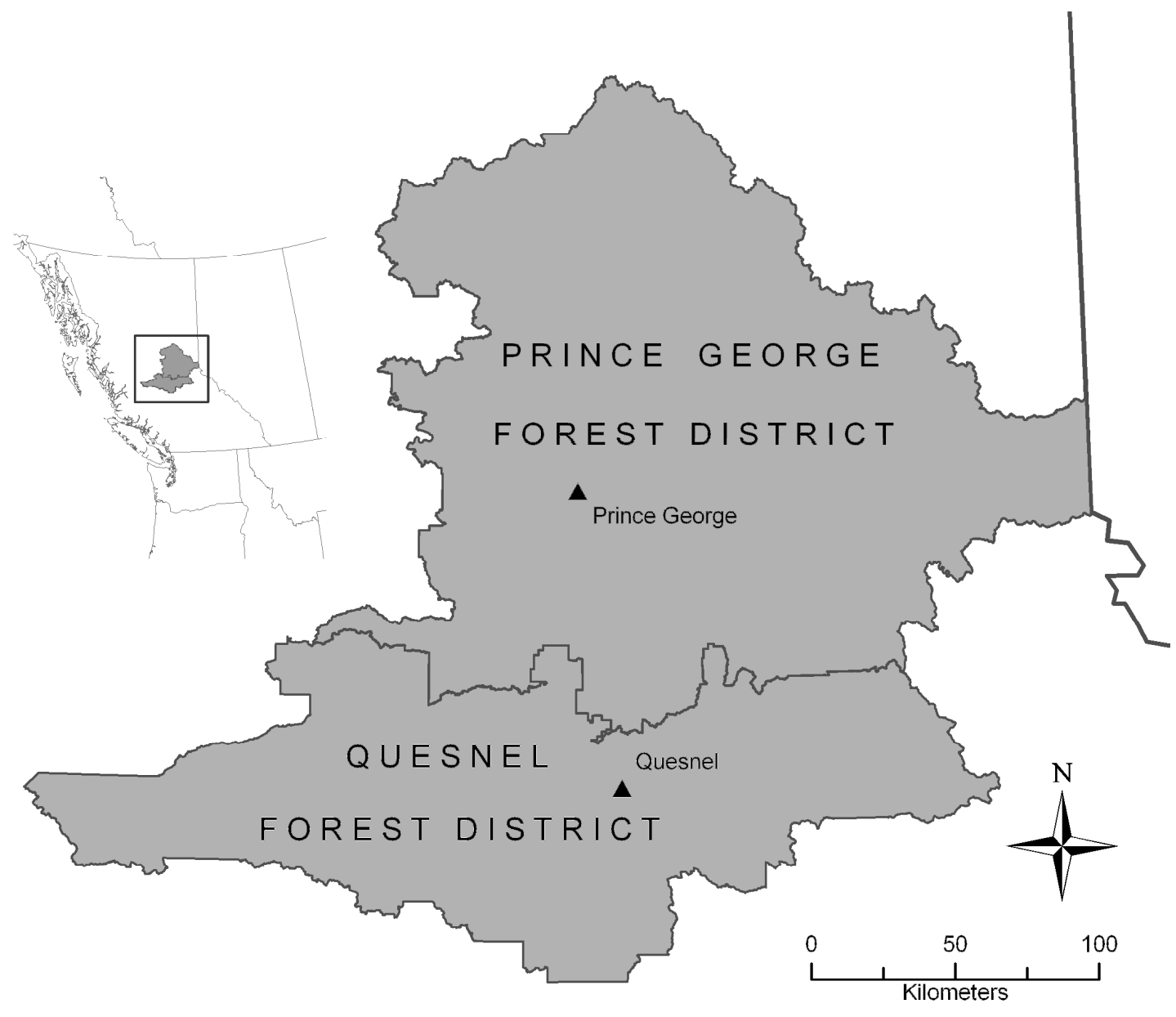

Fig. 1: Study area, the Prince George and Quesnel Forest Districts (5.5 million ha) located in British Columbia, Canada. 


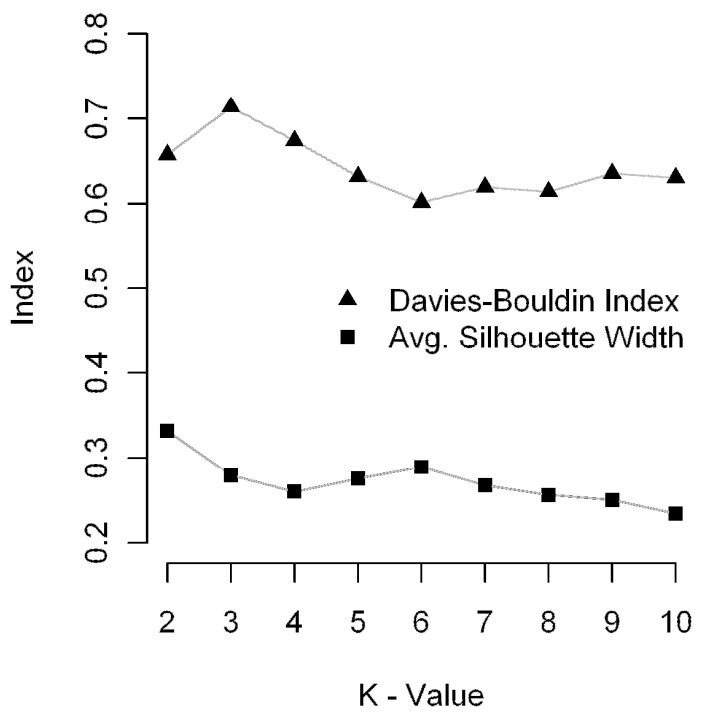

Fig. 2: Davies-Bouldin Index (DB) and Average Silhouette Width (ASW) results for $k$ values of $2-10$. Optimal $k$ is found at minimum DB and maximum ASW (in this case $k$ $=6)$. 


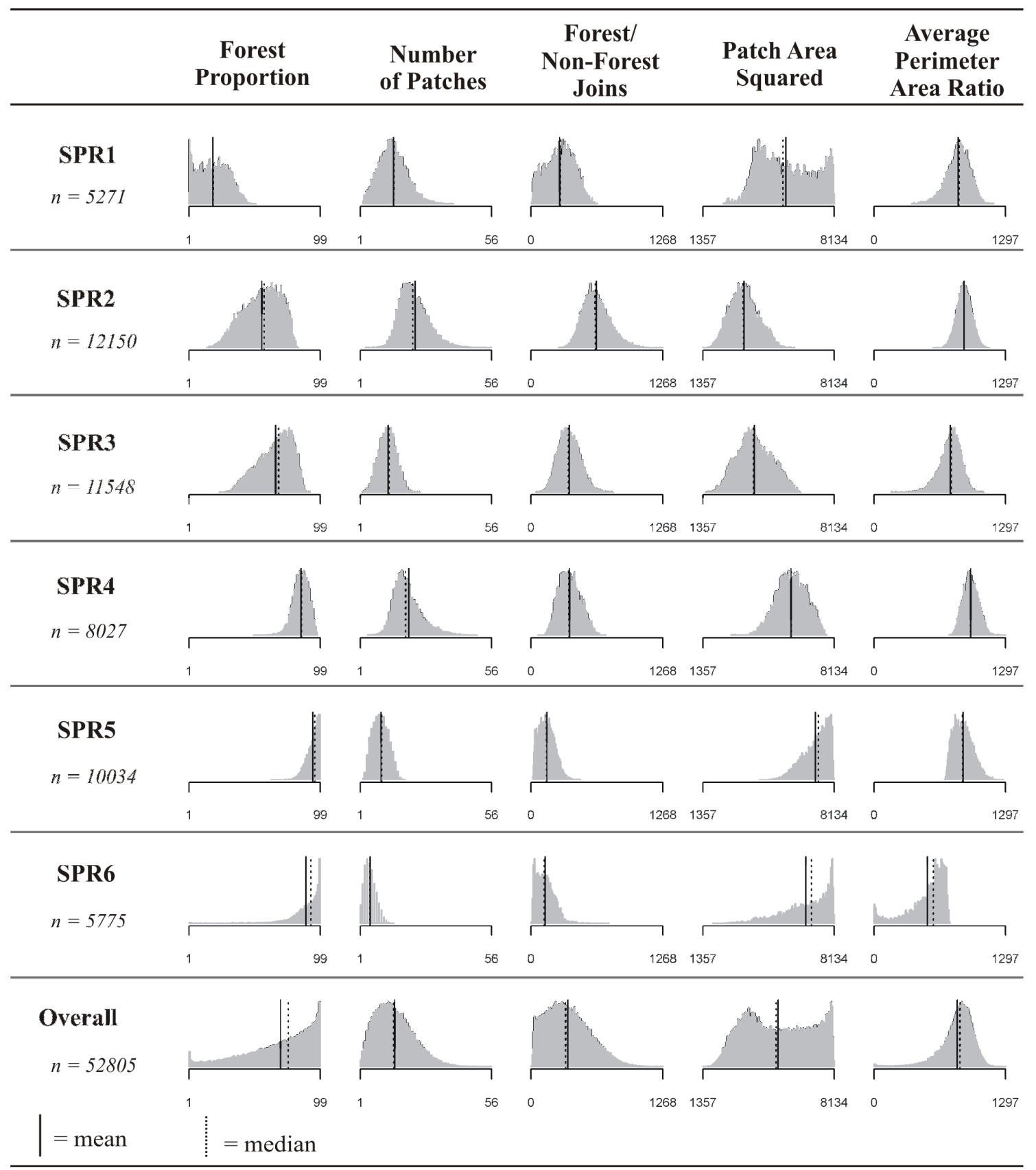

Fig. 3: Relative frequency histogram for each metric-SPR combination. Included are the mean and median values for each histogram. 


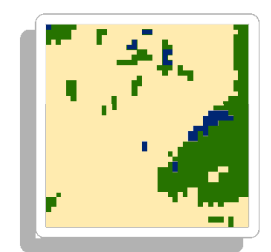

\section{SPR1}

SPR1 has the lowest level of forest proportion. It has moderate but variable number of patches and forest/non-forest join counts. It has high squared area of patches, but these are also quite variable. Perimeter-area ratio for SPR1 is very similar to the overall mean. This SPR has the highest level of forest fragmentation.

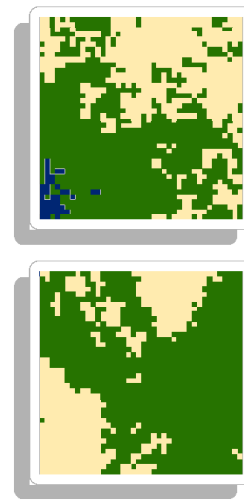

\section{SPR2}

SPR2 portrays medium levels of forest proportion, similar to that of SPR3. It has on average the most number of patches, which provide the lowest area squared value. The highest level of forest/non-forest joins was seen in this class indicating the least amount of spatial dependence in forest cover, and most forest edge.

\section{SPR3}

SPR3 is comprised of similar forest proportion to SPR2. Conversely to SPR2 it has a low number of patches and lower number of forest/non-forest joins. patch areas are comparable to SPR2, but low compared to other SPRs.

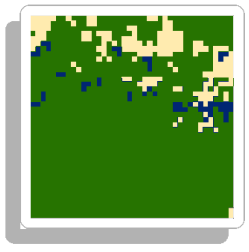

\section{SPR4}

SPR4 is a bit of an anomoly. It is characterized by relatively high forest composition, and high patch numbers but moderate forest/non-forest joins. Patch area squared measure for SPR4 is comparable to SPR1. SPR4 has the highest average perimeter area ratio of any of the SPRs.

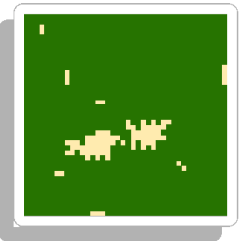

\section{SPR5}

SPR5 has the highest mean forest proportion. It is characterized by a low number of patches and low forest/non-forest joins. SPR 5 has high patch area squared measurements but similar perimeter area ratio to the overall mean.

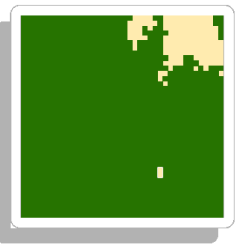

\section{SPR6}

SPR6 has the second highest mean forest proportion, and is most comparable to SPR5. It has lower number of patches then SPR5. Forest/non-forest joins and patch area squared measure are highly variable for SPR6. It's distinguishing feature is that it contains the lowest average perimiter-ratio of all SPRs. It is the SPR with the lowest forest fragmentation.

\section{Forest $\square$ Non-Forest $\square$ Other}

Fig. 4: Medoid landscapes for each SPR. Medoids are the central object in each cluster of the multivariate clustering. They are the representative landscape for each SPR. SPR0 and SPR100 are not shown but represent no forest and all forest, respectively. 

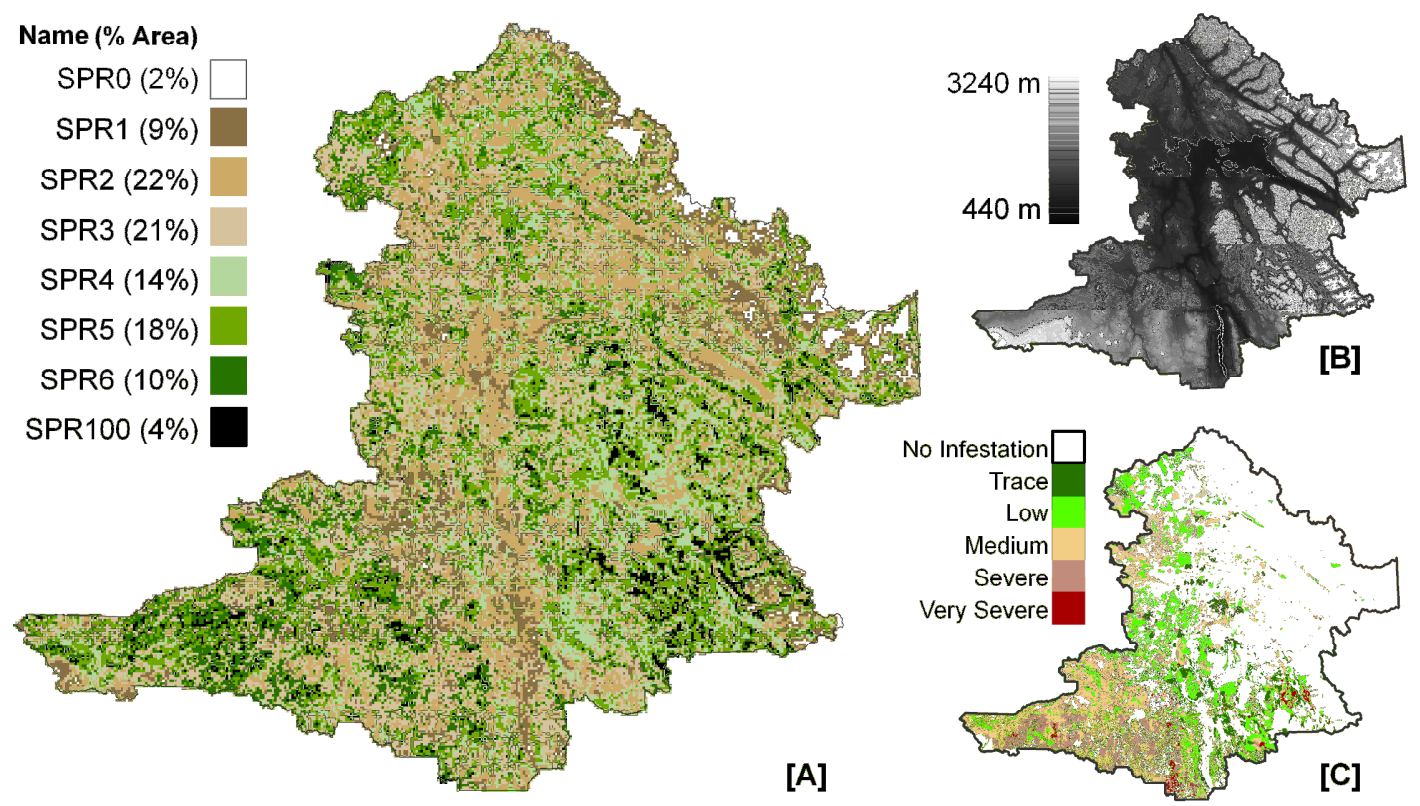

Fig. 5: Map of spatial pattern regions - SPR [A], across the Prince George and Quesnel Forest Districts in British Columbia, Canada. Ancillary information, such as elevation [B], and mountain pine beetle infestation severity levels for 2006 [C], can assist interpretation of SPR. 